\title{
Peripheral perfusion and acute mountain sickness: is there a link?
}

\author{
Adam C McDonnell ${ }^{1,2^{*}}$, Ola Eiken ${ }^{3}$, Igor B Mekjavic ${ }^{1}$ \\ From 15th International Conference on Environmental Ergonomics (ICEE XV) \\ Portsmouth, UK. 28 June - 3 July 2015
}

\section{Introduction}

It has been suggested that there is an interaction between acute mountain sickness, body temperatures and autonomic responses [1]. We tested this hypothesis by monitoring the circadian rhythm of peripheral perfusion reflected in the proximal to distal skin temperature gradient $(\Delta \mathrm{Tp}-\mathrm{d})$ during acute exposure of active and inactive (bedrest experimental protocol) subjects to acute normobaric hypoxia [2].

\section{Methods}

Thirty-six males participated in a total of 58 hypoxic exposures within the framework of three separate studies: LunHab (11 participants; two 10 day hypoxic confinements: $\mathrm{P}_{\mathrm{I}} \mathrm{O}_{2}=103 \mathrm{mmHg}$, simulated altitude of 3,000 m), PlanHab, (11 participants; two 21 day hypoxic confinements: $\mathrm{P}_{\mathrm{I}} \mathrm{O}_{2}=89.6 \mathrm{mmHg}$, simulated altitude of 4,000 m), HECS (14 participants; one 10 day hypoxic confinement: $\mathrm{P}_{\mathrm{I}} \mathrm{O}_{2}=88.2 \mathrm{mmHg}$, simulated altitude of $4,175 \mathrm{~m}$ ). On the first day of exposure to the simulated hypoxic condition, all participants of each study entered the hypoxic area at 9:00. Proximal to distal skin temperature gradient (calf and toe respectively, $\Delta \mathrm{Tc}-\mathrm{t}$ ) was recorded continuously from 10:00 for $20 \mathrm{hrs}$ on this first day of exposure (D1). The participants completed the Lake Louise Mountain Sickness (LLMS) question in the evening of the first day between 20:00 and 21:00. Distal and proximal skin temperatures were recorded at 1-minute intervals and then averaged into 60-minute epochs. The $\Delta$ Tc-t data was collated into two groups, those who presented with acute mountain sickness (AMS) and those who did not (nAMS).

\footnotetext{
* Correspondence: adam.mcdonnell@ijs.si

'Department of Automation, Biocybernetics and Robotics, Jozef Stefan Institute, Jamova Cesta 39, 1000 Ljubljana, Slovenia

Full list of author information is available at the end of the article
}

\section{Results}

Of the 58 exposures, sixteen resulted in participants presenting with mild symptoms of AMS on D1 of the hypoxic exposure (4.2 (1.3)). The nAMS group (42 exposures) gave an average rating of $0.4(0.7)$ on the LLMS questionnaire. The $\Delta$ Tc-t measured in the AMS group increased from $4.1(3.4){ }^{\circ} \mathrm{C}$ at $17: 00$ to $5.1(3.7){ }^{\circ} \mathrm{C}$ at 18:00 and to $5.0(3.7){ }^{\circ} \mathrm{C}$ at 19:00. The nAMS group had a $\Delta$ Tc-t of $2.6(2.9){ }^{\circ} \mathrm{C}$ at $18: 00$ and $3.1(3.1){ }^{\circ} \mathrm{C}$ at 19:00. A significant difference $(\mathrm{p}<0.05)$ in the $\Delta$ Tc- $t$ gradient between the AMS and nAMS group persisted until 19:00 on D1 of the hypoxic exposure. A non-significant difference $(\mathrm{p}=0.06)$ was observed between 19:00 and 20:00. At 21:00 the difference in $\Delta \mathrm{Tc}-\mathrm{t}$ between the two groups had abated, whereby both groups showed significant vasodilatation $(\mathrm{p}<0.05)$ of the toes thereafter and throughout the night compared to the daytime. There were no differences between groups in terms of age, body mass, body fat \% or $\mathrm{VO}_{2 \max }$.

\section{Conclusions}

The main finding of the current study is that daytime vasoconstriction of the periphery seen during hypoxic confinement is more pronounced in those suffering from AMS during the evening hours (17:00 to 19:00). This increased hypoxia-induced vasoconstriction in individuals with AMS suggests that they may be at a greater risk of cold injury when exposed to extreme cold at high altitude. Acknowledgements: The research leading to these results has received funding from the European Union's Framework Programme (2007-2013) under grant agreement no. 284438 (project PlanHab: Planetary Habitat Simulation), the European Space Agency (ESA) Programme for European Cooperating States (ESTEC/ Contract No. 40001043721/11 / NL / KML: Planetary 
Habitat Simulation) and the Slovene Research Agency (Project L3-4328).

\section{Authors' details}

'Department of Automation, Biocybernetics and Robotics, Jozef Stefan Institute, Jamova Cesta 39, 1000 Ljubljana, Slovenia. ${ }^{2}$ Jozef Stefan International Postgraduate School, Jamova Cesta 39, 1000 Ljubljana, Slovenia. ${ }^{3}$ Department of Environmental Physiology, Swedish Aerospace Physiology

Centre, Royal Institute of Technology, Stockholm, Sweden.

Published: 14 September 2015

\section{References}

1. Loeppky JA, Icenogle MV, Maes D, Riboni K, Scotto P, Roach RC: Body temperature, autonomic responses, and acute mountain sickness. High Alt Med Biol 2003, 4(3):367-373.

2. McDonnell AC, Eiken O, Mekjavic PJ, Mekjavic IB: Circadian rhythm of peripheral perfusion during 10-day hypoxic confinement and bed rest. Eur J Appl Physiol 2014, 114(10):2093-2104.

doi:10.1186/2046-7648-4-S1-A46

Cite this article as: McDonnell et al:: Peripheral perfusion and acute mountain sickness: is there a link? Extreme Physiology \& Medicine 2015 4(Suppl 1):A46.

\section{Submit your next manuscript to BioMed Central} and take full advantage of:

- Convenient online submission

- Thorough peer review

- No space constraints or color figure charges

- Immediate publication on acceptance

- Inclusion in PubMed, CAS, Scopus and Google Scholar

- Research which is freely available for redistribution

Submit your manuscript at www.biomedcentral.com/submit 